\title{
RECOMENDAÇÃO DE ADUBAÇÃO NITROGE NADA PARA O MILHO NO RS E SC ADAPTADA AO USO DE CULTURAS DE COBERTURA DO SOLO, SOB SISTEMA PLANTIO DIRETO(1)
}

\author{
T. J . C. AMADO (2), J . MIELNICZUK ${ }^{(3)} \&$ C. AITA ${ }^{(4)}$
}

\begin{abstract}
RESUMO
O nitrogênio, na maioria das situações, é o nutriente que mais influencia o rendimento do milho. 0 manejo da adubação nitrogenada deve satisfazer o requerimento da cultura com o mínimo de risco ambiental. Para tanto, é necessário que a recomendação da dose de adubo nitrogenado seja a mais exata possível. A generalização do uso do sistema de plantio direto e culturas de cobertura, no Sul do Brasil, criou a necessidade de ser a recomendação da adubação nitrogenada adaptada a este novo cenário agrícola. 0 presente trabalho, além de considerar o teor de MO e a expectativa do rendimento de grãos de milho na recomendação da adubação nitrogenada conforme preconiza a CFS-RS/SC (1995), propõe a introdução de um terceiro parâmetro que é a contribuição em $\mathbf{N}$ das culturas de cobertura antecedente. $\mathbf{O}$ efeito das culturas de cobertura foi considerado em três situações: leguminosas em cultivo soltei ro, gramíneas em cultivo solteiro e consorciações. No caso de leguminosas e gramíneas em cultivo solteiro, a influência na disponibilidade de $\mathbf{N}$ foi considerada com base na produção de matéria seca, enquanto, nas consorciações, a proporção da leguminosa foi o principal fator considerado. A recomendação de adubação apresentada neste trabalho não dispensa acompanhamento de campo, visando a ajustes que se fizerem necessários, especialmente porque sistemas de produção, baseados em culturas de cobertura, dependem de processos biológicos influenciados por condições de clima, manejo e solo, que devem ser acompanhados localmente.
\end{abstract}

Termos de indexação: fertilidade do solo, adubos verdes, decomposição de resíduos, Zea mays.

\footnotetext{
(1) Recomendação de adubação nitrogenada para a cultura do milho a partir do ano 2002 no Rio Grande do Sul e Santa Catarina aprovada pela CFS-RS/SC. Recebido para publicação em fevereiro de 2001 e aprovado em julho de 2001.

(2) Professor Adjunto do Departamento de Solos da Universidade Federal de Santa Maria - UFSM. Centro de Ciências Rurais. CEP 97119-900 Santa Maria (RS). Bolsista do CNPq. E-mail:tamado@ccr.ufsm.br

(3) Professor Titular atuando como colaborador do Departamento de Solos da Faculdade de Agronomia, Universidade Federal do Rio Grande do Sul - UFRGS. CEP 90001-970 Porto Alegre (RS). Bolsista do CNPq.

(4) Professor Adjunto do Departamento de Solos da UFSM. Bolsista do CNPq. E-mail: caita@ccr.ufsm.br
} 


\title{
SUMMARY: RECOMMENDATION OF NITROGEN FERTILIZATION FOR NO-TILL CORN IN RS AND SC, ADAPTED TO THE USE OF SOIL COVER CROPS
}

\begin{abstract}
For most conditions, nitrogen is the nutrient that most affects corn yidd. Nitrogen management should meet this crop requirement with a minimum environmental risk. To achievethis goal, nitrogen fertilization recommendation should beas preciseas possible The overall adoption of no-till and cover crops in Southern Brazil demands an adaptation of such recommendation. This recommendation was based on theCFS-RS/ SC (1995) and its main modification was taking into account thecontribution of the previ ous cover crop to $\mathrm{N}$ availability, besi des theorganic matter and yield goal previ ously used. The cover crop effect was consi dered under threesituations: legumes, grass and mixture. For legumes and grass, dry mass production was used to estimate $\mathrm{N}$ contribution. $\mathrm{F}$ or the mixture, legume participation was themain factor consi dered. Nitrogen fertilizer recommendati on presented in this work does not dismiss field evaluation, since residue decomposition is a biological process influenced by climate, soil and management that must be determined locally.
\end{abstract}

Index terms: Soil fertility, cover crops, residue decomposition, Zea mays.

\section{INTRODUÇÃO}

O nitrogênio é o nutriente requerido em maior quantidade pelas gramíneas e, por isso, em muitas situações, ésupridoinsuficientemente. Emanos nos quais as condições dimáticas são favoráveis à cultura do milho, a quantidade de $\mathrm{N}$ requerida para otimizar a produtividade de grãos pode alcançar valores superiores a $150 \mathrm{~kg} \mathrm{ha}^{-1}$. Quantidade tão el evada dificilmente será suprida somentepel o solo, havendo necessidade de usar outras fontes suplementares deste nutriente. Dentre estas, destaca-se a utilização, isolada ou combinada, deadubos minerais, leguminosas e estercos.

O manejo do $\mathrm{N}$ em sistemas agrícolas deve considerar os elevados riscos ambientais, uma vez que este nutriente está sujeito a perdas por erosão, lixiviação, desnitrificação e volatilização. Stanford (1973) e Keeney (1982) definem o manejo ideal da adubação nitrogenada como sendo aquele que permite satisfazer a necessidade da cultura com o mínimo de risco ambiental. Para tanto, éimportante que a quantidade de $\mathrm{N}$ por aplicar nas culturas seja a mais exata possível, minimizandotanto os excessos, que prejudicam a qualidade ambiental e oneram o produtor, quanto aos deficits, que comprometem o rendimento projetado.

A recomendação de adubação nitrogenada para o milho, apresentada pela Comissão Fertilidade Sul (CFS-RS/SC, 1995), é baseada no teor de matéria orgânica do solo (MO) ena expectativa derendimento. Tal recomendaçãoapresentou resultados satisfatórios, durante muitos anos, nos estados do Rio Grande do Sul e Santa Catarina. No entanto, com o avanço do sistema plantio direto e a generalização da utilização deculturas de cobertura e rotação deculturas, surgiu a necessidade de adaptar a recomendação de $\mathrm{N}$ a este novo cenário agrícola.

Para exemplificar, Pöttker \& Roman (1994), avaliando a recomendação de adubação nitrogenada da CFS-RS/SC (1995) para o milho em sucessão à aveia preta no sistema plantio direto, encontraram subestimação da dose. Os autores atribuíram este resultado à presença de resíduos com alta relação carbono/nitrogênio $(\mathrm{C} / \mathrm{N})$ da cultura de cobertura, diminuindo a disponibilidade de $\mathrm{N}$ para o milho. Por outro lado, quando leguminosas são utilizadas antecedendo ao milho, há possibilidade designificativa redução na adubação nitrogenada mineral. A recomendação da CFS-RS/SC (1995) prevê, nestes casos, redução de até $50 \%$ na dose de $\mathrm{N}$ a ser aplicada no milho. Todavia, essa recomendação não considera a quantidade de $\mathrm{N}$ presente na fitomassa da leguminosa.

Para Amado et al. (2000), as informações básicas requeridas para otimizar a recomendação da adubação nitrogenada em sistemas de manejo conservacionista induem: (a) estimativa do potencial de mineralização do N do solo; (b) contribuição da cultura de cobertura antecedente (quantidade de $\mathrm{N}$ mineralizada ou imobilizada); (c) requerimento de $\mathrm{N}$ pela cultura econômica, para atingir um rendimento projetado; (d) expectativa da eficiência de recuperação do $\mathrm{N}$ disponível das diferentes fontes (solo, cultura de cobertura e fertilizante mineral); (e) histórico de cultivos anteriores da área.

Este trabalho objetivou incluir na atual recomendação de adubação nitrogenada do RS e SC o efeito da cultura de cobertura antecedentena disponibilidade de $\mathrm{N}$ ao milho sob sistema plantio direto. 


\section{BASE EXPERIMENTAL}

Utilizandoresultados de experimentos realizados, durante vários anos, em Entidades de Pesquisa e Universidades do Sul do Brasil relacionados no quadro 1, foram feitas algumas generalizações descritas a seguir.

\section{Nitrogênio total no solo e mineralização}

A utilização do sistema plantio direto favorece o aumento do nitrogênio total do solo, o qual é detectado inicial mente na camada mais superficial e, com o passar dos anos, estende-se para camadas mais profundas (Bayer \& Mielniczuk, 1997; Amado et al., 1999). O aumento do estoque de $\mathrm{N}$ no solo está relacionado com a diminuição nas perdas, especialmente por erosão, e com o aumento das adições pel a fixação biol ógica do $\mathrm{N}$ atmosférico (F BN) e pela ciclagem do $\mathrm{N}$ disponível no solo (Dalal \& Meyer, 1986; Bayer \& Miel niczuk, 1997). O histórico das culturas, especialmente leguminosas, e das adubações utilizadas irá determinar o tamanho deste estoque (Teixeira et al., 1994), também influenciado pelas condições de sol o e clima.

Deve-se destacar que a grande proporção deste $\mathrm{N}$ encontra-sena forma orgânica, queérelativamente estável e não prontamente disponível às culturas. Assim, o N orgânico necessita ser mineralizado por meio da biomassa microbiana do solo, a qual é influenciada por fatores bióticos e abióticos. Desta forma, nem sempre um estoque el evado de $\mathrm{N}$ total no sol o representa el evada disponibilidade deste nutriente às culturas.

Nos primeiros anos de plantio direto, é comum verificar menor disponibilidade de $\mathrm{N}$ às plantas quando comparado ao preparo convencional (Phillips et al., 1980; Blevins et al., 1983; F reitas, 1988; Rosso, 1989; Sá, 1992). Várias são as razões atribuídas a este fato: maior imobilização, menor mineralização, recuperação do estoque de MO, dentre outras. Amado et al. (2000) encontraram que o coeficiente de mineralização do $\mathrm{N}$ do solo foi influenciado pelo sistema de preparo adotado. Assim, no preparo convencional, a mineralização foi $91 \%$ superior àquela verificada no plantio direto, sugerindo, neste último, um ambiente menos oxidativo (Reicosky \& Lindstrom, 1993). Com isto, justifica-se a menor disponibilidadeinicial de N no plantio direto; porém, a médio e longo prazo, o aumento do estoque deste nutriente deverá compensar o menor coeficiente de mineralização (Sá, 1996; Bayer \& Mielniczuk, 1997) eos dois sistemas deverão apresentar disponibilidade deN pelo menos semelhante (Gilliam \& Hoyt, 1987).

A atual recomendação quanto a época de aplicação de adubação nitrogenada no milho é de até $30 \mathrm{~kg} \mathrm{ha}^{-1}$ na semeadura e o restante em cobertura durante o ciclo da cultura (CFS-RS/SC, 1995). Blinder et al. (2000) encontraram que, em situações de baixa disponibilidade de $\mathrm{N}$ do solo, os mel hores rendimentos de milho foram obtidos com antecipação da adubação nitrogenada. No Brasil, recentes trabalhos também têm destacado a importância deaumentar a disponibilidade de $\mathrm{N}$ nos estádios iniciais de desenvolvimento do milho sob sistema plantio direto, anteci pando a apl icação deste nutriente(Yamada, 1996; Sá, 1996; Basso, 1999). No entanto, a substituição da adubação nitrogenada de cobertura no mi lho pela aplicação em pré-semeadura tem-se revelado uma estratégia de risco econômico eambiental, especial mente quando em situações de el evada precipitação (Wolschick, 2000; Basso \& Ceretta, 2000). Considerando que as informações disponíveis ainda são escassas, há necessidade de intensificar as pesquisas sobre a melhor época de aplicação do N no milho sob plantio direto.

\section{Produção de matéria seca e concentração de N da fitomassa de culturas de cobertura}

A quantidade de $\mathrm{N}$ na fitomassa das leguminosas cultivadas na entressafra das culturas comerciais é elevada, situando-se na faixa de 50 a $200 \mathrm{~kg} \mathrm{ha}^{-1}$, geralmente com valores médios próximos a $120 \mathrm{~kg} \mathrm{ha}^{-1}$ (Reeves, 1994). Tradicionalmente, estas plantas eram incorporadas ao solo, visando à imediata li beração dos nutrientes acumulados na fitomassa, sendo por isto denominadas adubos verdes. No entanto, vários resultados depesquisa doSul do Brasil têm demonstrado que estas mesmas plantas podem ser utilizadas em cobertura, pois praticamente os

Quadro 1. Localização, classificação do solo e tempo de realização dos experimentos de manejo que serviram como base para a recomendação de adubação nitrogenada para a cultura do milho

\begin{tabular}{lllc}
\hline Instituição & Localização & Classificação Solo & Tempo de condução \\
\hline & & & ano \\
UFRGS & Eldorado do Sul (RS) & Argissolo Vermelho & 15 \\
UFSM & Santa Maria (RS) & Argissolo Vermelho & 6 \\
UFSM & Santa Maria (RS) & Argissolo Vermelho & 4 \\
FUNDACEP & Cruz Alta (RS) & Latossolo Vermelho & 5 \\
EMBRAPA & Passo Fundo (RS) & Latossolo Vermelho & 3 \\
EPAGRI & Chapecó (SC) & Latossolo Roxo & 8 \\
\hline
\end{tabular}


mesmos benefícios de incremento da disponibilidade de $\mathrm{N}$ podem ser obtidos, quando os resíduos culturais destas plantas são deixados na superfície do solo (Calegari et al., 1993; Da Ros \& Aita, 1996).

A elevada concentração de nitrogênio na fitomassa das leguminosas éatribuída principalmente à FBN. Padovan et al. (2000) e Villatoro (2000) estimaram que aproximadamente $85 \%$ do $\mathrm{N}$ da fitomassa da mucuna teve como origem a FBN. Em muitas situações, são recomendáveis a inoculação das sementes, com Rhizobium a correção da acidez ea fertilização, com vistas em aumentar a eficiência da simbiose e, conseqüentemente, a FBN. A concentração de $\mathrm{N}$ na fitomassa da leguminosa, quando as condições mínimas são atendidas, é pouco variável entre os anos. Por outro lado, a produção de matéria seca éinfluen-ciada por condições dimáticas, edáficas efitossani-tárias, entreoutras (Amado, 1991; Calegari et al., 1993). Assim, normalmente, é a produção de matéria seca que irá determinar o total de $\mathrm{N}$ a ser adicionado ao solo pelas leguminosas (Holderbaum et al., 1990).

O aumento da disponibilidadede $\mathrm{N}$ para a primeira cultura cultivada em sucessão às leguminosas (efeito imediato) é percebi do em vários experimentos no Sul do Brasil (Pons et al., 1984; Derpsch et al., 1985; Teixeira et al., 1994; Aita et al., 1994). No entanto, resultados de pesquisa que utilizam ${ }^{15} \mathrm{~N}$ têm sugerido que a maior proporção do $\mathrm{N}$ da fitomassa das leguminosas tem como destino o solo (L add et al., 1981; Harris \& Hesterman, 1990), ficando acumulado na forma de $\mathrm{N}$ orgânico. Assim, o uso de leguminosas podeaumentar tambéma disponibilidadede $\mathrm{N}$ do solo a médio e longo prazo (efeito residual), reduzindo a necessidade de outras fontes de $\mathrm{N}$ para maximizar o rendimento de culturas utilizadas na rotação (Evanylo, 1990; Reeves, 1994).

Amado et al. (1999), comparando o efeito imediato e o residual do uso de leguminosas, concluíram que o primeiro proporcionou incremento de $45,6 \%$ no rendimento do milho, enquanto o segundo, de $19 \%$. Assim, para fins de recomendação de adubação nitrogenada, a cultura imediatamente anterior é a queterá maior influência sobrea disponibilidade de $\mathrm{N}$ para a cultura comercial.

E mbora as gramíneas, como a aveia, apresentem el evada capacidade de absorção e acumulação de N na planta, alcançando valores tão el evados quanto $147 \mathrm{~kg} \mathrm{ha}^{-1}$ (Heinzmann, 1985), sua contribuição na disponibilidade de $\mathrm{N}$ é inferior à das leguminosas. Amado et al. (1999), avaliando a decomposição de resíduos de aveia no sistema plantio direto, conduíram que apenas $20 \%$ do N contido nas plantas foi liberado nas primeiras quatro semanas após o manejo, resultando em assincronismo com a demanda inicial do milho. A el evada capacidade de absorção de $\mathrm{N}$ das gramíneas constitui importante estratégia para reduzir os riscos de contaminação do lençol freático com nitrato eaumentar a ciclagem de $\mathrm{N}$ durante a entressafra das culturas comerciais.

\section{Decomposição dos resíduos, liberação e imobilização de $\mathbf{N}$}

A dinâmica do $\mathrm{N}$ das leguminosas é complexa, pois a associação do carbono com o $\mathrm{N}$ nos resíduos governa o padrão de decomposição. As condições climáticas de umidade e temperatura da primavera do Sul do Brasil propiciam que a decomposição dos resíduos de leguminosas de inverno e crucíferas (nabo forrageiro), mesmo quando deixados na superfície do solo, ocorra de forma rápida.

Pavinato (1993), Amado et al. (1999) eAita et al . (2001) encontraram que, transcorridas quatro semanas do manejo de plantas destas famílias botânicas, houve a liberação de aproximadamente $70 \%$ do $\mathrm{N}$ da fitomassa. De fato, tem-se observado quea liberação do $\mathrm{N}$ das culturas de cobertura segue o padrão de decomposição dos resíduos. Com isto, visando otimizar o aproveitamento do $\mathrm{N}$ da fitomassa, recomenda-se que a semeadura do milho seja feita em um período de tempo não superior a uma semana após o manejo das leguminosas (Aita et al., 2001).

Quando resíduos de gramíneas são adicionados à superfície do solo, verifica-se uma decomposição muito mais lenta que aquela das leguminosas e crucíferas. Dentre os fatores que concorrem para isto, destacam-se a el evada relação $\mathrm{C} / \mathrm{N}$ e, em muitas situações, a reduzida disponibilidade de $\mathrm{N}$ mineral do solo. Assim, ao invés de um fornecimento do $\mathrm{N}$ da gramínea para a cultura em sucessão, geralmente verifica-se um decréscimo na disponibilidade deste nutriente, resultando em menor absorção de $\mathrm{N}$ pel o milho, especialmente em situação de ausência ou limitada fertilização nitrogenada mineral (Aita et al., 1994; Pavinato et al., 1994).

Com base na menor disponibilidade de $\mathrm{N}$ e em possíveis efeitos al elopáticos, recomenda-se um interval o de uma a duas semanas entre o manejo de gramíneas, especialmente o azevém, e o plantio de milho (Ruedell, 1995). Sá (1996) sustentou que estes efeitos são transitórios e, com o decorrer dos anos de plantio direto e do uso de rotação de culturas, a imobilização de $\mathrm{N}$ pelas gramíneas tendea diminuir.

As consorciações de culturas de cobertura (gramíneas, leguminosas, crucíferas e outras) apresentam vários benefícios à melhoria da qualidade do solo. Especificamente quanto ao N, as gramíneas e as crucíferas atuam na ciclagem do $\mathrm{N}$ mineral do solo, reduzindo os riscos de lixiviação, enquanto as leguminosas adicionam este nutriente pela FBN, contribuindo para o aumento da disponibilidade de $\mathrm{N}$ para as culturas em sucessão. A decomposição de resíduos, neste caso, depende da proporção das espécies que compõem a consorciação e da relação C/N resultante (Henrichs et al., 2001). Porém, de modo geral, a vel ocidade de decomposição dos resíduos culturais das espécies consorciadas é intermediária em relação aos cultivos isolados de leguminosas ou crucíferas e aos de gramíneas. 
A contribuição de $\mathrm{N}$ das consorciações, para as culturas em sucessão, é muito dependente da proporção das leguminosas. Quando há predomínio de gramíneas, parte do $\mathrm{N}$ adicionado pelas leguminosas pode ser imediatamente imobilizado pelos microrganismos durante a decomposição dos resíduos, reduzindo a disponibilidade destenutriente para a cultura em sucessão (Decker et al., 1987).

Henrichs et al. (2001), avaliando o milho cultivado em sucessão à consorciação de aveia +ervilhaca em diferentes proporções, concluíram que a proporção de $10 \%$ de gramínea $+90 \%$ da leguminosa foi a que mais favoreceu a absorção de $\mathrm{N}$ e a produtividade de grãos. As consorciações, além de terem potencial de balanço positivo sobre a disponibilidade de $\mathrm{N}$, apresentam várias outras vantagens, tais como: maior produção de matéria seca, maior cidagem de nutrientes, redução da infestação de pragas, aumento da atividade biológica, maior resistência a estresses, reduzindo a variação interanual na quantidade de resíduos adicionados ao solo (Calegari \& Vieira, 1999; Henrichs et al., 2001).

\section{RECOME NDAÇÃO DE ADUBAÇÃO NITRO- GE NADA PARA O MILHO ADAPTADA AO USO DE CULTURAS DE COBERTURA NO SISTEMA PLANTIO DIRETO}

A recomendação de adubação nitrogenada proposta neste trabalho (Quadro 2) baseia-se na recomendação da CFS-RS/SC (1995), a qual se mostrou adequada às condições do Sul do Brasil. A principal modificação introduzida foi considerar a cultura de cobertura antecedente, além do teor de MO e da expectativa de rendimento já utilizados como critério para recomendação de adubação nitrogenada mineral. Desta forma, procurou-se contabilizar a contribuição das principais fontes de $\mathrm{N}$ ao milho; neste caso, MO e culturas de cobertura, sendo a fertilização mineral um complemento que visa satisfazer o requerimento da cultura para al cançar uma produtividade de grãos projetada.

Outra alteração em relação à recomendação da CFS-RS/SC (1995) éo acréscimo deumnível (superior

\section{Quadro 2. Recomendação de adu bação nitrogenada para o milho adaptada ao sistema plantio direto e ao uso de culturas de cobertura no Rio Grande do Sul e Santa Catarina}

\begin{tabular}{|c|c|c|c|c|c|c|c|c|c|c|c|c|}
\hline \multirow{4}{*}{$\begin{array}{l}\text { Cultura de cobertura } \\
\text { antecedente }^{(5)}\end{array}$} & \multicolumn{12}{|c|}{ Expectativa de produtividade de grãos de milho (Mg ha-1)(1) } \\
\hline & \multicolumn{3}{|c|}{$<3$} & \multicolumn{3}{|c|}{ 3-6 } & \multicolumn{3}{|c|}{$6-9$} & \multicolumn{3}{|c|}{$>9$} \\
\hline & \multicolumn{12}{|c|}{ Matéria orgânica (\%) } \\
\hline & $<2,5$ & 2,5-5,0 & $>\mathbf{5 , 0}$ & $<2,5$ & $2,5-5,0$ & $>5,0$ & $<2,5$ & $2,5-5,0$ & $>5,0$ & $<2,5$ & 2,5-5,0 & $>5,0$ \\
\hline & & & & & & $-\mathrm{kg} \mathrm{r}$ & de $N$ & & & & & 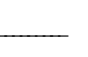 \\
\hline \multicolumn{13}{|l|}{ Leguminosa(2) } \\
\hline $\begin{array}{l}\text { Baixa produção } \\
\text { Média produção } \\
\text { Alta produção }\end{array}$ & $\begin{array}{c}40 \\
20 \\
0\end{array}$ & $\begin{array}{r}30 \\
0 \\
0\end{array}$ & $\begin{array}{r}20 \\
0 \\
0\end{array}$ & $\begin{array}{l}80 \\
60 \\
50\end{array}$ & $\begin{array}{l}70 \\
50 \\
40\end{array}$ & $\begin{aligned} & 50 \\
\leq & 40 \\
\leq & 30\end{aligned}$ & $\begin{array}{r}120 \\
100 \\
90\end{array}$ & $\begin{array}{l}90 \\
60 \\
50\end{array}$ & $\begin{array}{l}70 \\
40 \\
30\end{array}$ & $\begin{array}{l}160 \\
140 \\
120\end{array}$ & $\begin{array}{l}140 \\
120 \\
100\end{array}$ & $\begin{array}{r}100 \\
90 \\
80\end{array}$ \\
\hline \multicolumn{13}{|l|}{ Consorciação(3) } \\
\hline $\begin{array}{l}\text { Predomínio gramínea } \\
\text { Equilibrada } \\
\text { Predomínio leguminosa }\end{array}$ & $\begin{array}{l}60 \\
40 \\
20\end{array}$ & $\begin{array}{r}40 \\
30 \\
0\end{array}$ & $\begin{array}{r}\leq 30 \\
20 \\
0\end{array}$ & $\begin{array}{r}100 \\
80 \\
60\end{array}$ & $\begin{array}{l}80 \\
70 \\
50\end{array}$ & $\begin{array}{r}60 \\
50 \\
\leq 40\end{array}$ & $\begin{array}{l}140 \\
120 \\
100\end{array}$ & $\begin{array}{r}100 \\
90 \\
80\end{array}$ & $\begin{array}{l}80 \\
70 \\
60\end{array}$ & $\begin{array}{l}160 \\
160 \\
140\end{array}$ & $\begin{array}{l}140 \\
140 \\
120\end{array}$ & $\begin{array}{r}100 \\
100 \\
90\end{array}$ \\
\hline \multicolumn{13}{|l|}{ Gramínea(4) } \\
\hline $\begin{array}{l}\text { Baixa produção } \\
\text { Média produção } \\
\text { Alta produção } \\
\text { Pousio inverno }\end{array}$ & $\begin{array}{l}80 \\
80 \\
80 \\
80\end{array}$ & $\begin{array}{l}60 \\
60 \\
60 \\
60\end{array}$ & $\begin{array}{l}\leq 40 \\
\leq 40 \\
\leq 40 \\
\leq 40\end{array}$ & $\begin{array}{l}110 \\
120 \\
140 \\
130\end{array}$ & $\begin{array}{r}90 \\
100 \\
100 \\
90\end{array}$ & $\begin{array}{r}\leq 65 \\
80 \\
80 \\
\leq 65\end{array}$ & $\begin{array}{l}160 \\
160 \\
170 \\
160\end{array}$ & $\begin{array}{l}100 \\
110 \\
130 \\
120\end{array}$ & $\begin{array}{l}70 \\
80 \\
90 \\
80\end{array}$ & $\begin{array}{l}180 \\
180 \\
200 \\
180\end{array}$ & $\begin{array}{l}160 \\
160 \\
180 \\
160\end{array}$ & $\begin{array}{l}120 \\
120 \\
140 \\
120\end{array}$ \\
\hline
\end{tabular}

\footnotetext{
(1) A expectativa de produtividade é baseada em anos com precipitação pluviométrica normal. ${ }^{(2)}$ Leguminosas com baixa produção de matéria seca (MS) $=<2 \mathrm{Mgha}^{-1}$; média produção de $\mathrm{MS}=2-3 \mathrm{Mgha}^{-1}$; alta produção de $\mathrm{MS}=>3 \mathrm{Mg} \mathrm{ha}^{-1}$. (3) Consorciação equilibrada ( $1 / 2$ de leguminosa $+1 / 2$ de gramíneas); consorciação com predomínio de leguminosa $=2 / 3$ leguminosa $+1 / 3$ gramínea e consorciação com predomínio de gramínea =2/3 gramínea $+1 / 3$ leguminosa. ${ }^{(4)}$ Gramíneas: baixa produção de $M S=<2$ Mg ha-1; média produção de MS =2-4 Mg ha ${ }^{-1}$; alta produção de $\mathrm{MS}=>4 \mathrm{Mg} \mathrm{ha}^{-1}$. Obs.: Nabo forrageiro pode ser considerado como uma leguminosa de média produção para sol os com $>2,5 \%$ de $\mathrm{MO}$ e produção de $\mathrm{MS}>3,0 \mathrm{Mg}$ ha-1 e leguminosa de baixa produção para sol os $<2,5 \%$ de $\mathrm{MO}$ e produção de $\mathrm{MS} \leq 3,0 \mathrm{Mg} \mathrm{ha}^{-1}$. ${ }^{(5)}$ Milho em rotação anual durante o verão com a soja poderá ter a recomendação de adubação nitrogenada reduzida em até $20 \%$.
} 
a $9 \mathrm{Mg} \mathrm{ha}^{-1}$ ) na expectativa de produtividade de grãos de milho (Quadro 2). Neste caso, objetivou-se contemplar aquelas situações cujo potencial de produtividade da cultura é el evado em virtude das condições edafocl imáticas favoráveis e da utilização intensiva de tecnol ogia, como irrigação, fertilização, genética e práticas culturais. Com o objetivo de simplificar o manuseio deste quadro, as cinco dasses de teor de MO da recomendação anterior foram reduzidas para três: baixo $(<2,5 \%)$, médio $(2,5$ a $5,0 \%)$ e alto (>5,0\%). As conseqüências desta redução nas classes de MO sobre a exatidão na recomendação de $\mathrm{N}$ ao milho deverão ser avaliadas nos próximos anos.

A contribuição das culturas de cobertura antecedente ao milho foi considerada em três situações: leguminosas em cultivo solteiro, gramíneas em cultivo sol tei ro e consorciações.

No caso de leguminosas e gramíneas em cultivo solteiro, o efeito na disponibilidade de $\mathrm{N}$ foi considerado com base na produção de matéria seca (Fiorin et al., 1998). Assim, para leguminosas, consideraram-se: como baixa produção de matéria seca, valores <2 $\mathrm{Mg} \mathrm{ha}^{-1}$; como média produção, valores entre 2 e $3 \mathrm{Mg} \mathrm{ha}^{-1}$, e como el evada produção, valores $>3 \mathrm{Mg} \mathrm{ha}^{-1}$. Neste caso, quanto maior a produção de matéria seca, maior o fornecimento de N para o milho em sucessão. Para as gramíneas, foram considerados como de baixa produção de matéria seca valores $<2 \mathrm{Mg} \mathrm{ha}^{-1}$; como média produção, valores entre 2 e $4 \mathrm{Mg} \mathrm{ha}^{-1}$, e como el evada produção, valores $>4 \mathrm{Mg} \mathrm{ha}^{-1}$. A contribuição das gramíneas, quanto ao fornecimento de $\mathrm{N}$ ao milho, foi estimada como sendo muito pequena ou nula em relação ao pousio invernal. Especialmente para situações de el evada produção de matéria seca de gramíneas, projetou-se decréscimo na disponibilidade de N pela imobilização microbiana.

No caso das consorciações, a disponibilidade de $\mathrm{N}$ é mais influenciada pela composição da consorciação do que pela produção total de matéria seca. Portanto, considerou-se como consorciação com predomínio de gramíneas aquela com 2/3 ou mais da fitomassa pertencente a esta família botânica; equilibrada aquela com 1/2 de gramíneas e 1/2 de leguminosas, e predomínio de leguminosas aquela com 2/3 ou mais da fitomassa pertencente a esta família botânica. Neste caso, quanto maior a proporção de leguminosas na consorciação, maior a disponibilidade de N para a cultura em sucessão. Para fins de recomendação de adubação nitrogenada, considerou-se que uma consorciação equilibrada teria efeito semel hante na disponibilidade de $\mathrm{N}$ ao de uma leguminosa com baixa produção de matéria seca, bem como uma consorciação com predomínio de leguminosas seria equivalente àquela de uma leguminosa com média produção de matéria seca (Quadro 2). Esta informação necessita ser confirmada por um número maior de resultados experimentais.
O nabo forrageiro tem sido muito utilizado em cobertura do sol o no sul do Brasil, em virtude de seu baixo custo, vel ocidade de crescimento e cicl o curto. Uma das principais características dessa cultura é a el evada capacidade de ciclagem de $\mathrm{N}$, contribuindo para o aumento da disponi bilidade deste nutriente. Com base nisto, considerou-se que, em solos com baixo teor de MO e produção de matéria seca $\leq 3 \mathrm{Mg} \mathrm{ha}^{-1}$, a sua contribuição seria semel hante a de uma leguminosa de baixa produção. J á em solos com médio a al to teor de MO e produção de matéria seca > $3 \mathrm{Mg} \mathrm{ha}^{-1}$, a sua contri buição seria equival ente a de uma leguminosa com média produção.

No tratamento pousio de inverno, foi mantida a recomendação anterior da CFS-RS/SC (1995), acrescida de mais um nível de expectativa de produtividade de grãos. O milho, quando em rotação anual com a soja, ainda pode ter a dose de adubo nitrogenado recomendada (Quadro 2) reduzida em $20 \%$, considerando o efeito rotação. A expectativa de rendimento apresentada nesse quadro foi el aborada com base em condições climáticas favoráveis e em padrões tecnológicos propostos para a cultura do milho descritos em Recomendações (1997).

O quadro 2 foi el aborado com base nos resultados experimentais disponíveis. Deve-se destacar que esta é uma recomendação e, portanto, deve ser utilizada como um referencial na tomada de decisão da dose de $\mathrm{N}$ a ser utilizada, não dispensando acompanhamento de campo, visando ajustes que se fizerem necessários, especial mente porque sistemas de produção baseados em culturas de cobertura são dependentes de processos biológicos influenciados por condições de clima, manejo e sol o que devem ser acompanhados localmente.

\section{PERSPECTIVAS}

A proposta atual de recomendação de adubação nitrogenada deve ser dinâmica, incorporando novos resultados de pesquisa, assim que forem disponibilizados. Além disto, pretende-se adaptá-la a situações em que outras fontes de N são utilizadas, tais como: culturas de cobertura de verão intercalares ao milho (mucuna, feijão-de-porco, crotalária e outras) e adubação orgânica (estercos de aves, suínos e bovinos). O tempo de utilização de culturas de cobertura e do sistema plantio direto (efeito residual) deverá ser considerado futuramente, visando à redução na dose de adubação mineral recomendada.

\section{AGRADECIMENTOS}

Às I nstituições, Universidades e Pesquisadores que disponibilizaram resultados experimentais e 
sugestões que fundamentaram a elaboração desta recomendação de adubação nitrogenada. Em especial a SirioWiethölter, Carlos A. Ceretta, Delmar Pöttker, LeandroWildner, Milton da Veiga, Faustino Andreola, Márcio Voss, I banor Anghinoni, J ackson Fiorin e Gilbert Argenta.

\section{LITE RATURA CITADA}

AMADO, T.J.C. Adubação verde de inverno para o Alto Vale do Itajaí. R. Agropec. Catarinense, 4:4-7, 1991.

AMADO, T.J.C.; MIELNICZUK, J .; FERNANDES, S.B.V. \& BAYER, C. Culturas de cobertura, acúmulo de nitrogênio total no solo e produtividade de milho. R. Bras. Ci. Solo, 23:679-686, 1999.

AMADO, T.J.C.; MIELNICZUK, J. \& FERNANDES, S.B.V. Leguminosas e adubação mineral como fontes de suprimento de nitrogênio ao milho em sistemas de preparo do solo. R. Bras. Ci. Solo, 24:179-189, 2000.

AITA, C.; CERETTA, C.A.; THOMAS, A.L.; PAVINATO, A. \& BAYER, C. Espécies de inverno como fonte de nitrogênio para o milho no sistema de cultivo mínimo e feijão em plantio direto. R. Bras. Ci. Solo, 18:101-108, 1994.

AITA, C.; BASSO, C.J .; CERETTA, C.A.; GONÇALVES, C.N. \& DA RÓS, C.O. Plantas de cobertura de solo como fonte de N ao milho. R. Bras. Ci. Solo, 25:157-165, 2001.

BASSO, C.J . Épocas de aplicação de nitrogênio para o milho cultivado em sucessão a plantas de cobertura de solo, sob sistema plantio direto. Santa Maria, Universidade Federal de Santa Maria, 1999. 91p. (Tese de Mestrado)

BASSO, C.J . \& CERETTA, C.A. Manejo do nitrogênio no milho em sucessão a plantas de cobertura de solo, sob plantio direto. R. Bras. Ci. Solo, 24:905-915, 2000.

BAYER, C. \& MIELNICZUK, J. Nitrogênio total de um solo submetido a diferentes métodos de preparo e sistemas de cultura. R. Bras. Ci. Solo, 21:235-239, 1997.

BLINDER, D.L.; SANDER, D.H. \& WALTERS, D.T. Agron. J ., 92:1228-1236, 2000.

BLEVINS, R.L.; THOMAS, G.M.; SMITH, M.S.; FRYE, W.W. \& CORNELIUS, P.L. Changes in soil properties after 10 years continuous non-tilled and conventionally tilled corn. Soil Till. Res., 3:135-146, 1983.

CALEGARI, A. \& VIEIRA, M.J. Técnicas de controle da erosão. In: CASTRO FILHO, C. \& MUZI LLI, O., eds. Uso e manejo dos sol os de baixa aptidão agrícola. Londrina, I APAR, 1999. p.53-99.

CALEGARI , A.; MONDARDO, A.; BULISANI, E.A.; WILDNER, L.P.; COSTA, M.B.B.; ALCÂNTARA, P.B.; MIYASAKA, S. \& AMADO, T.J.C. Adubação verde no Sul do Brasil. 2 $2^{\text {a }}$ edição. Rio deJ aneiro, Assessoria e Serviços a Projetos em Agricultura Alternativa, 1993. 346p.

COMISSÃO DE FERTILIDADE DO SOLO - CFRS/SC. Recomendações de adubação e calagem para o Estado do Rio Grande do Sul e Santa Catarina. 3.ed. Passo Fundo, Núcleo Regional Sul, Empresa Brasileira de Pesquisa Agropecuária, 1995. 223p.
DALAL, R.C. \& MAYER, R.J . Long-term trends in fertility of soils under continuos cultivation and cereal cropping in Southern Queensland. I. Overall changes in soil properties and trends in winter cereal yields. Aust. J . Soil Res., 24:265279, 1986.

DA ROS, C.O. \& AITA, C. Efeito de espécies de inverno na cobertura do solo e fornecimento de nitrogênio ao milho em plantio direto. R. Bras. Ci. Solo, 20:135-140, 1996.

DECKER, A.M.; HOLDERBAUM, J.F.; MULFORD, R.F.; MEISINGER, J.J. \& VOUGH, L.R. Fall-seeded legume nitrogen contributions to no-till corn production. In: ROLE OF LEGUMES IN CONSEVATION TILLAGE SYSTEMS, Athens, 1987. Proceedings. Ankeny, Soil Conservation Society of America, 1987. p.21-22.

DERPSCH, R. SIDIRAS, N. \& HEINZMANN, F.X. Manejo do solo com coberturas verdes de inverno. Pesq. Agropec. Bras., 20:671-773, 1985.

EVANYLO, G.K. Dryland corn response to tillage and nitrogen fertilization. I. Growth-yield-N relationships. Comm. Soil Sci. Plant, 21:137-170, 1990.

FREITAS, V.H. Eficiência de sistemas de preparo do solo e de culturas no fornecimento de nitrogênio para o milho. Porto Alegre, Universidade Federal do Rio Grande do Sul, 1988. 148p. (Tese de Mestrado)

FIORIN,J .E.; CANAL, I.N. \& CAMPOS, B.H. Fertilidade do solo. In: CAMPOS, B.H., coord. A cultura do milho em plantio direto. Cruz Alta, Fundacep Fecotrigo, 1998. p.15-54.

GILLIAM, J.W. \& HOYT, G.D. Effect of conservation tillage on fate and transport of nitrogen. In: LOGAN, T.J .; DAVIDSON, J.M.; BAKER, J.L. \& OVERCASH, M.R., eds. Effects of conservation tillage on groundwater quality: nitrates and pesticides. Chelsea, Lewis, 1987. p.217-240.

HARRIS, G.H. \& HESTERMAN, O.B. Quantifying the nitrogen contribution from alfafa to soil and two succeding crops using Nitrogen-15. Agron. J ., 82:129-134, 1990.

HEI NZMANN, F.X. Resíduos culturais de inverno e assimilação de nitrogênio por culturas de verão. Pesq. Agropec. Bras., 20:1021-1030, 1985

HENRICHS, R.; AITA, C.; AMADO, T.J.C. \& FANCELLI, A.L. Cultivo consorciado de aveia e ervilhaca: relação $\mathrm{C} / \mathrm{N}$ da fitomassa e produtividade do milho em sucessão. R. Bras. Ci. Solo, 25:331-340, 2001

HOLDERBAUM, J.F.; DECKER, A.M.; MEISINGER, J J .; MULFORD, F.R. \& VOUGH, L.R. Fall-seeded legume cover crops for no-tillage corn in the humid East. Agron. J., 82:117-124, 1990.

KEENEY, D.R. Nitrogen management for maximum efficiency and minimum pollution. In: STEVENSON, F.J. Nitrogen in agricultural soils. Madison, Soil Science Society of America, 1982. p.605-649.

LADD, J.N.; OADES, J.M. \& AMATO, M. Distribution and recovery of nitrogen from legume residues decomposing in soils sown to wheat in the field. Soil Biol. Biochem., 13:251256, 1981 
PADOVAN, M.P.; BALIEIRO, F.C.; SISTI, C.P.J .; OKITO, A.; FRANCH, C.M.; ARAÚJ O, E.S.; MARTINS, L.M.V.; PEOPLES, M.B.;ALVES, B.J .R.; URQUIAGA, S.;BODDEY, R.M.; TEIXEIRA, F.C.P.; MILLER, K.L. \& LIMA, Q.S. Estimativa da fixação biológica de nitrogênio ( $F B N$ ) pela mucuna (Mucuna pruriens) consorciada com milho, sob cultivo orgânico, utilizando a técnica de abundância natural de ${ }^{15} \mathrm{~N}\left(\delta^{15} \mathrm{~N}\right)$. In: REUNIÃO BRASILEIRA DE FERTILIDADE DO SOLO E NUTRIÇÃO DE PLANTAS, 24., REUNIÃO BRASILEIRA SOBRE MICORRIZAS, 8., SIMPÓSIO BRASILEIRO DE MICROBIOLOGIA DO SOLO, 6., REUNIÃO BRASILEIRA DE BIOLOGIA DO SOLO, 3., 2000. Resumos. Santa Maria, Sociedade Brasileira de Ciência do Solo, 2000. p.24.

PAVINATO, A. Teores de carbono e nitrogênio do solo e produtividade de milho afetados por sistemas de culturas. Porto Alegre, Universidade Federal do Rio Grande do Sul, 1993. 122p. (Tese de Mestrado)

PAVINATO, A.; AITA, C.; CERETTA, C.A. \& BEVILÁQUA, G.P. Resíduos culturais de espécies de inverno e o rendimento de grãos de milho no sistema de cultivo mínimo. Pesq. Agropec. Bras., 29:1427-1432,1994.

PONS, A.L.; NUSS, C.N. \& PINTO, R.J.B. Efeito de doses de nitrogênio sobre o rendimento do milho, em cultivo mínimo e convencional após o cultivo da vica. In: REUNIÃO TÉCNICA ANUAL DO MILHO, 29., PortoAlegre, 1984. Ata. Porto Alegre, IPAGRO/EMATER-RS, 1984. p.97-98.

PÖTTKER, D. \& ROMAN, E. Efeito de resíduos de cultura e do pousio de inverno sobre a resposta do milho a nitrogênio. Pesq. Agropec. Bras., 29:763-770, 1994.

PHILLIPS, R.E.; BLEVINS, R.L.; THOMAS, G.W.; FRYE, W.W. \& PHILLIPS, S.H. No-tillage agriculture. Science, 208:1108-1113, 1980.

RECOMENDAÇÕES TÉCNICAS PARA A CULTURA DO MILHO NO ESTADO DO RIO GRANDE DO SUL. Porto Alegre, Fepagro, Emater/RS, Fundacep, 1997. 140p. (Boletim Técnico, n.4)
REEVES, D.W. Cover crops and rotations. In: HATFIELD, J.L. \& STEWART, B.A., eds. Crops residue management. Florida, Lewis, 1994. p.125-172. (Advances in Soil Science)

REICOSKY, D. \& LINDSTROM, M.J . Fall tillage method: effect on short carbon dioxide flux from soil. Agron. J., 85:12371243, 1993.

ROSSO, A. Manejo de culturas de cobertura do solo no inverno e sua relação com a produtividade do milho. Porto Alegre, Universidade Federal do Rio Grande do Sul, 1989, 117p. (Tese de Mestrado)

RUEDELL, J. Plantio direto na região de Cruz Alta. Convênio Fundacep/Basf. Fundacep-Fecotrigo:Cruz Alta, RS. 1995. $134 p$.

SÁ,J .C.M. Manejo da fertilidade do sol o no plantio direto. Castro, Fundação ABC, 1992. 57p.

SÁ, J.C.M. Manejo do nitrogênio na cultura do milho no sistema plantio direto. Passo Fundo, Aldeia Norte, 1996. 24p.

STANFORD, G. Rationale for optimum nitrogen fertilization in corn production. J. Environ. Qual., 2:159-166, 1973.

TEIXEIRA, L.A.J .;TESTA, V.M. \& MIELNICZUK, J . Nitrogênio do solo, nutrição e rendimento do milho afetados por sistemas de cultura. R. Bras. Ci. Solo, 18:207-214, 1994.

WOLSCHICK, D. Perdas de nitrogênio por lixiviação durante o ciclo de desenvol vimento da cultura do milho em condições de excesso hídrico. Santa Maria, Universidade Federal de Santa Maria, 2000, 79p. (Tese de Mestrado)

VILLATORO, M.A.A. Contribuição da adubação ver de como fonte de nitrogênio para as culturas de milho e sorgo. Rio de J aneiro, Universidade Federal Rural do Rio de J aneiro, 2000. 106p. (Tese de Mestrado)

YAMADA, T. Adubação nitrogenada no milho: quanto, como e quando aplicar? Piracicaba, POTAFÓs, 1996. p.15. (I nformativo Agronômico, 74) 